\title{
Estimation of steel slag parameters using thermal imaging and neural networks classification
}

by M. Wiecek*, R. Strakowski*, B. Wiecek*, R. Olbrycht*, T. Swiątczak*, W. Wittchen** and M. Borecki**

*Electronic Circuits and Thermography Div., Institute of Electronics, Technical University of Lodz, Poland, wiecek@p.lodz.pl **Institute for Ferrous Metallurgy, K. Miarki Street 12-14, 44-100 Gliwice, Poland, wwittchen@imz.pl

\section{Introduction}

In this work, the results of emissivity measurement for steelmaking slag in two spectral infrared ranges (MWIR and LWIR) are presented. The thermograms were acquired in the steelworks (fig. 3), during the discharge of the steelmaking slag (fig. 2), which occurs directly after the discharge of metal (fig. 1). The research confirmed significant difference of spectral emissivity between the metal and steelmaking slag during the discharge process $[5,6]$. The results are to be used for estimation of technological parameters of the steelmaking slag. The idea of the investigations presented in this paper relies on applying the neural network for the analysis of measurement results [1].

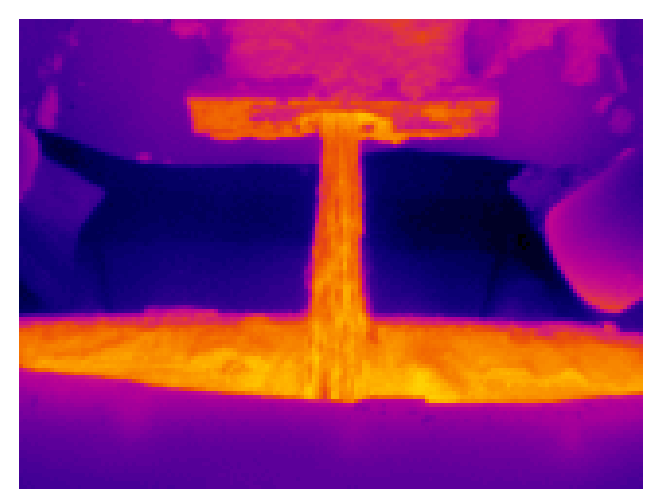

Fig. 1. Thermogram of metal pouring out of the discharge hole

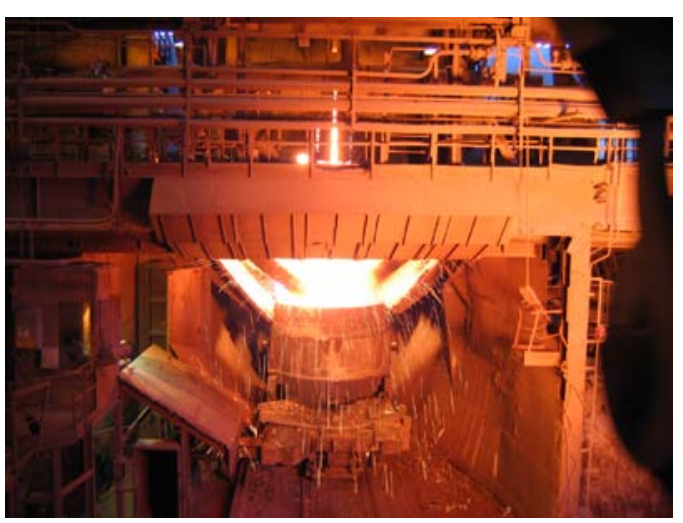

Fig. 3. Photograph of the discharge installation located in the steelworks

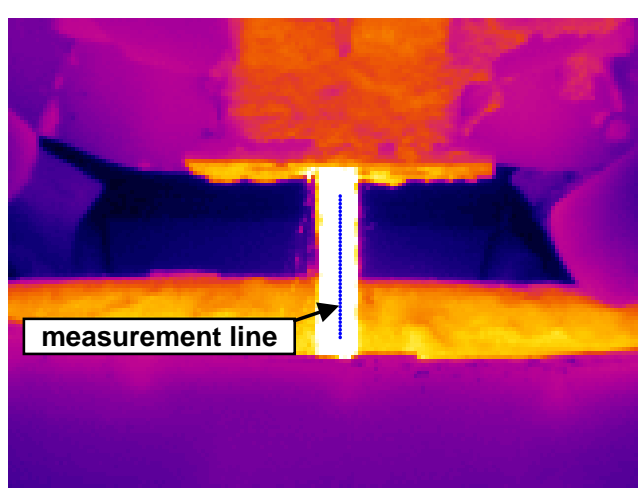

Fig. 2. Thermogram of steelmaking slag pouring out of the discharge hole with the line marked along the stream

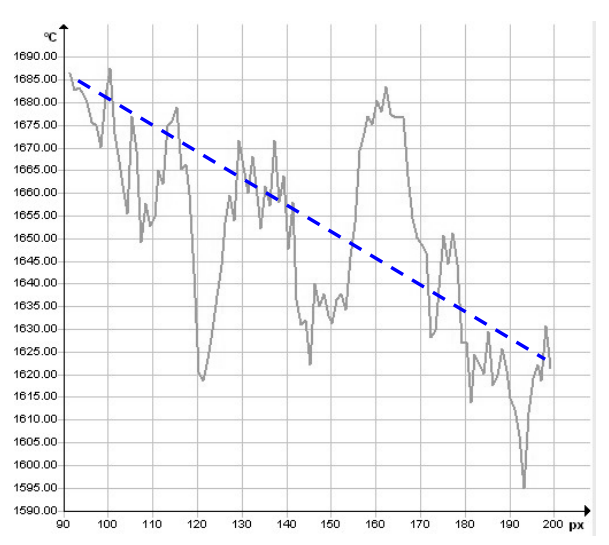

Fig. 4. Exemplary temperature distribution along the measurement line (fig. 2) with the blue trend line overlaid 


\section{Neural network approach}

Neural network in this research was used for thermal image classification. Different image signatures [1,2,3], such as temperature gradient along the stream (fig. 4), min and max temperature values, emissivity, chosen morphological features and technological parameters $[3,4]$ may be the input data for neural networks - fig. 5 . The output layer on the network may contain the different number of neurons according the number of slag classes used in the investigation. The simplest task can implement just a single neuron to differentiate the acceptable and non-acceptable product. Authors applied the neural network consisting of two input neurons, two neurons in the hidden layer and one output neuron, as shown in fig. 5. Input and hidden layer apply tansig neuron activation function (tan-sigmoid transfer function), while output neuron has logsig activation function (log-sigmoid transfer function) - fig. 5.
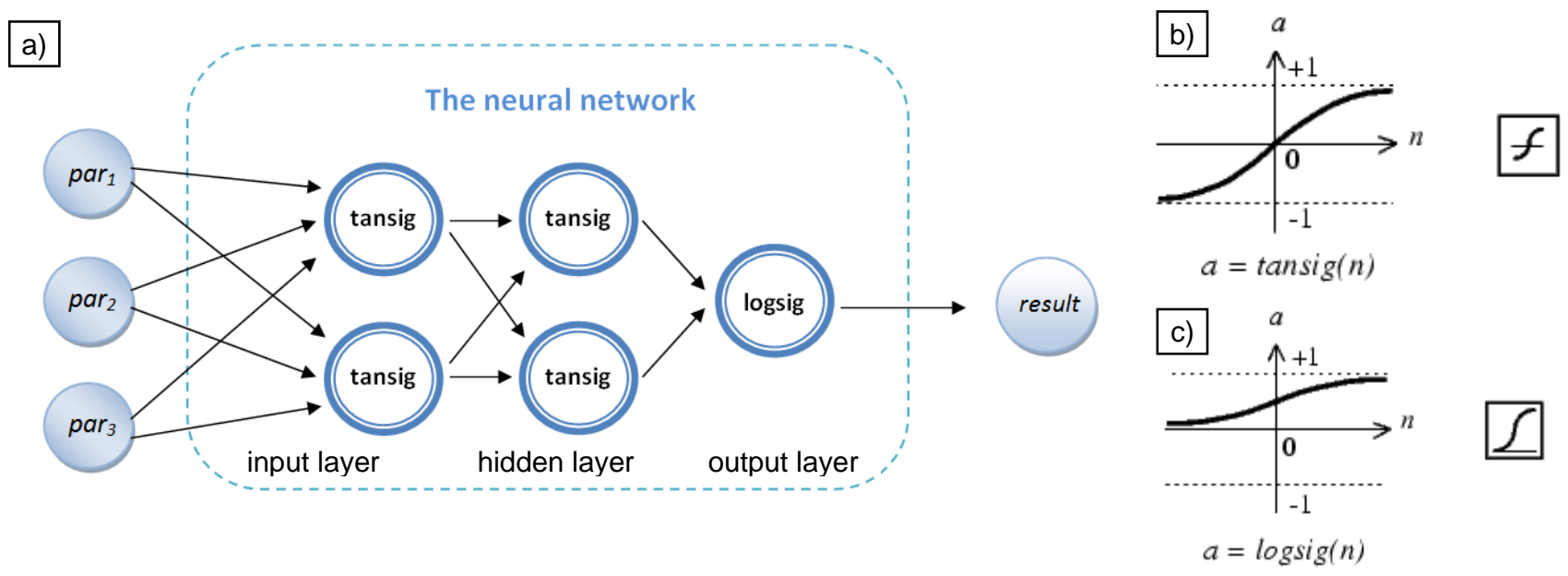

Fig. 5. a) The neural network for classification of the quality of the steelmaking slag, with b) tansig and c) logsig transfer functions

Learning process of the neural network is the crucial element of the overall approach. Authors have chosen for the research 11 thermal images showing steelmaking slag streams with different FeO content. All of them were chemically analyzed. In particular, we know the content of the $\mathrm{FeO}$ in the slag. This is a main technological parameter which should be estimated in the real process [3,4]. Knowing the FeO content and the values of the chosen thermal signatures of the slag, the learning process can be applied. Then the testing phase will be performed, in order to evaluate how effective is the proposed method for FeO content estimation.

\section{Analysis of the chosen parameters}

In case of this research, authors want to "teach" the neural network to determine whether the content of FeO in the steelmaking slag is high (more than $25 \%$ ) or low (less than $25 \%$ ). In the first case, the sequence should be classified as "class 0", while in the second - as "class 1". Should the neural network face any difficulty, in result it also may classify sequences as "class ?". To enable classification, it is necessary to provide the guideline, that determine the FeO content in the steelmaking slag. Authors have chosen three parameters as the guideline to distinguish between the low and high FeO content in the stream.

The parameter no. 1 is the slope of the regression line along the slag stream temperature distribution plot. It is calculated with the use a following algorithm:

1) the steelmaking slag stream is extracted from the thermogram by means of a linear thresholding (fig. 6 a),

2) for each row of the stream, the average value of its temperature in this row is calculated,

3) these values are plotted versus the row number (starting from the top), and the regression line is found (fig. $6 \mathrm{~b}$ ),

4) the slope $a$ of the regression line (given by the equation $y=a \cdot x+b$ ) is found. In case of example in fig. $6, a=-0,6$.

The parameter no. 2 is the skewness difference of histograms corresponding to the top (red square in fig. $6 \mathrm{c}$ ) and bottom (blue square in fig. $6 \mathrm{c}$ ) areas of the steelmaking slag stream. Skewness is a measure of histogram asymmetry around its average, according to equation (1). 


$$
S_{H}=\frac{\sum_{i=0}^{L-1}\left(i-\mu_{H}\right)^{3} p(i)}{\sigma_{H}{ }^{3}}
$$

The parameter no. 3 is the skewness calculated for the measurement lines placed along the stream. Exemplary measurement line is shown in fig. 6 (c) - marked yellow.
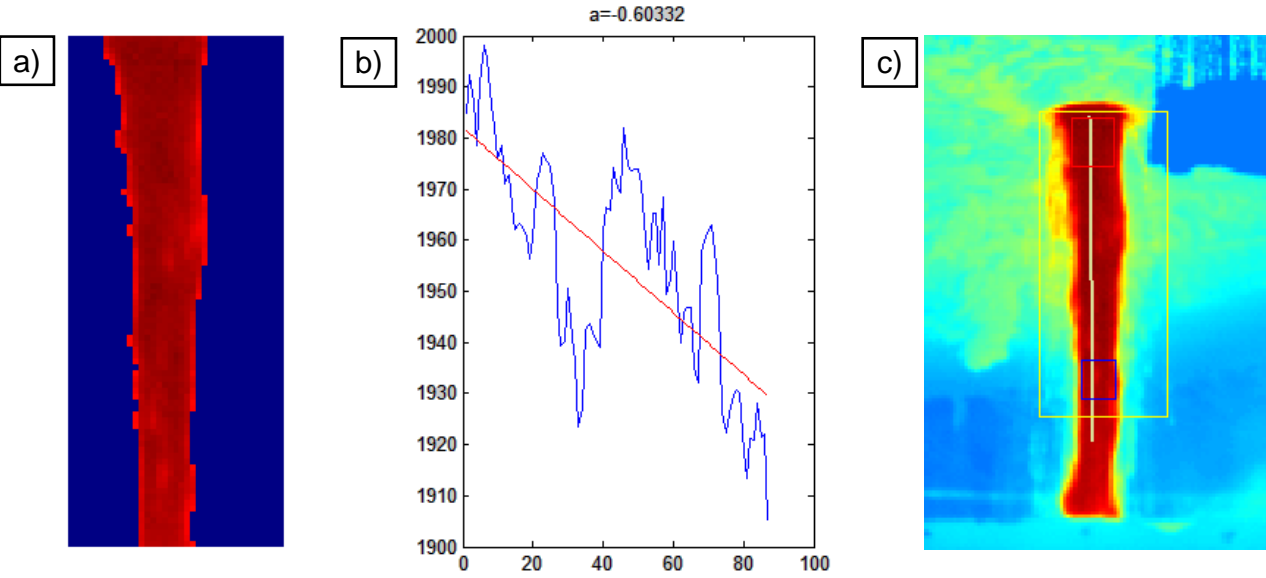

Fig. 6. a) The steelmaking slag stream thresholded from a thermogram,

b) its temperature distribution plotted versus the row number, with the regression line, c) the steelmaking slag stream with marked areas of skewness calculation

\section{Results}

Authors plotted the percentage FeO content in the steelmaking slag for each thermogram. There are three plots (fig. $7,8,9)$ showing those values in parallel with values of the calculated parameters (scaled), respectively $1,2,3$. To verify the correctness of classification done by the neural network, there were 11 tests conducted. For each test, one thermogram (corresponding to the test number) was chosen as a reference one in terms of steelmaking slag percentage content. The remaining ones were used to "teach" the neural network to distinguish between the low and high FeO content basing on the values of three calculated parameters. The tests proved, that the neural network is an efficient tool for evaluation of the FeO content in steelmaking slag streams.

To evaluate the classification efficiency, authors present the results of testing in table 1 . Each thermogram belongs to either class "0" if the steelmaking slag content is high (more than 25\%), or else class " 1 ". During each test, the neural network took 11 attempts to classify the thermogram, giving the output values from 0 to 1 . It was taken that the output in the range from 0 to 0,4 means that the thermogram belongs to class "0", while for values from 0,6 to 1 - class " 1 ". In case of classification difficulty, the output values from the neural network could have taken values from 0,4 to 0,6 , corresponding to an additional class "?". However, it was not the case during the tests.

In 7 of 11 cases, the correctness of classification was equal to $100 \%$, and only in one case, it was below $50 \%$. Overall, authors estimate the classification correctness to be about $85 \%$. 


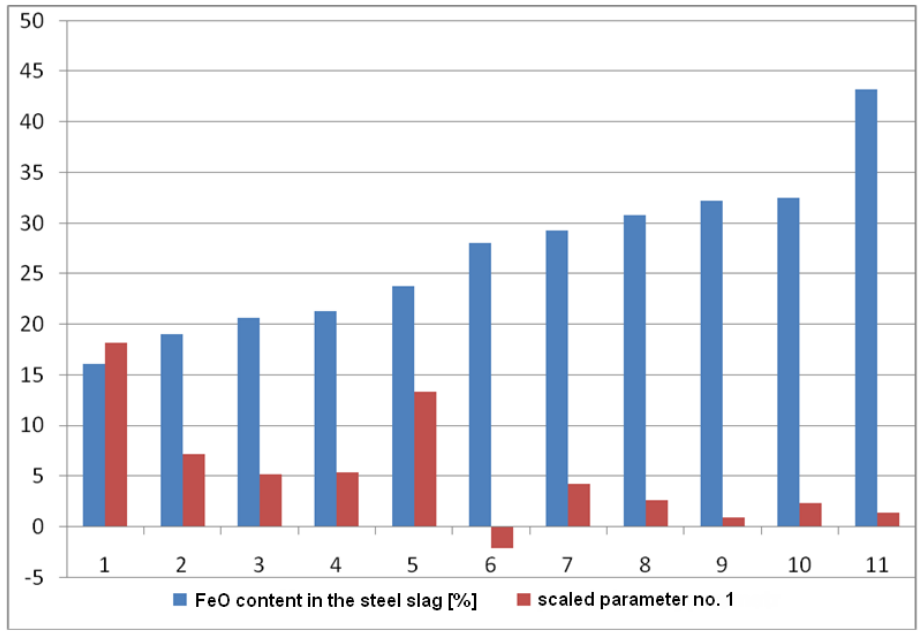

Fig. 7. FeO content in the steelmaking slag versus the scaled parameter no. 1

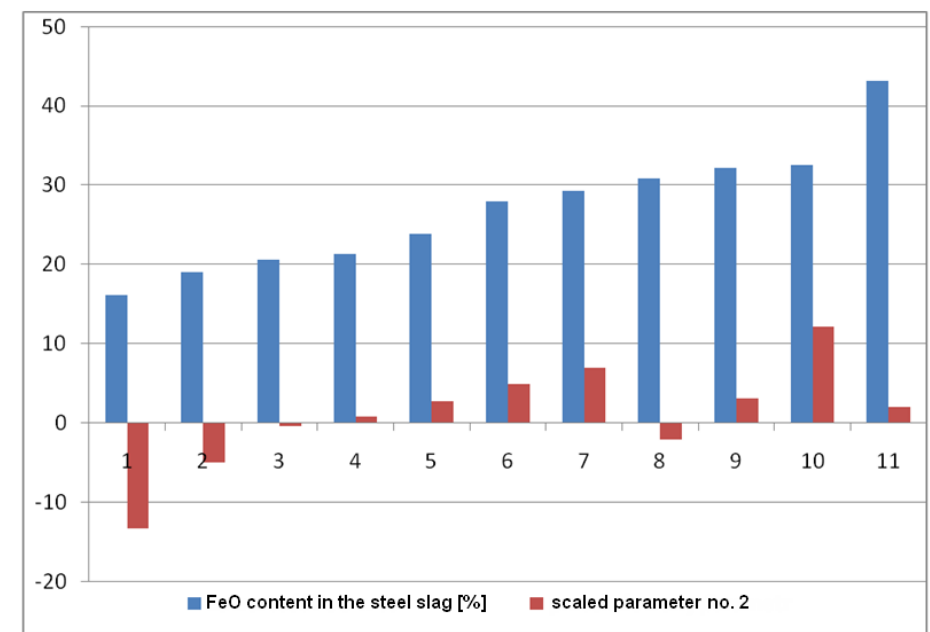

Fig. 8. FeO content in the steelmaking slag versus the scaled parameter no. 2

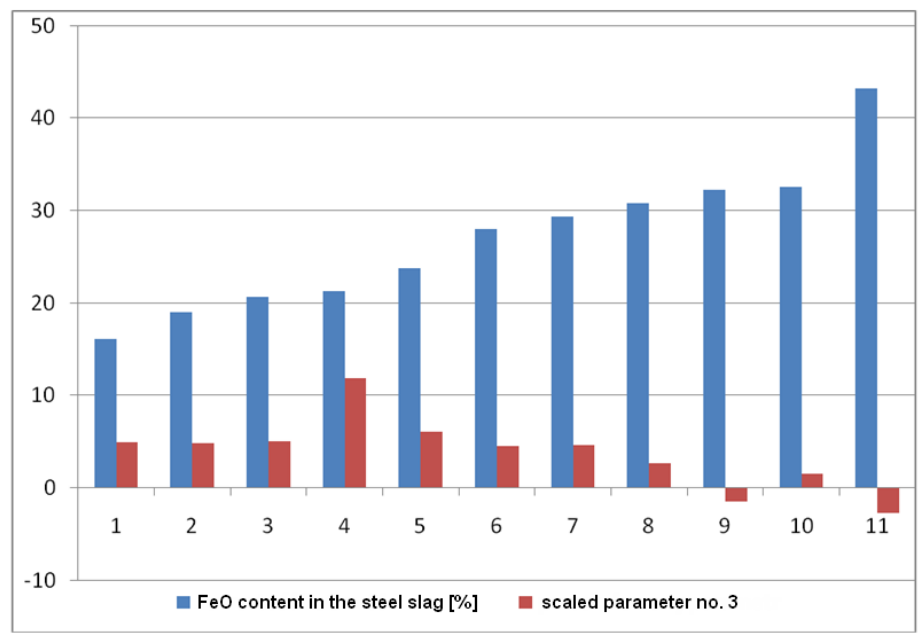

Fig. 9. FeO content in the steelmaking slag versus the scaled parameter no. 3 
Table 1. Classification results and correctness with the neural network

\begin{tabular}{|c|c|c|c|c|c|}
\hline \multirow[b]{2}{*}{$\begin{array}{c}\text { Thermogram } \\
\text { number }\end{array}$} & \multirow[b]{2}{*}{$\begin{array}{c}\text { Thermogram } \\
\text { class }\end{array}$} & \multicolumn{3}{|c|}{ Classification results } & \multirow[b]{2}{*}{ Correctness [\%] } \\
\hline & & Class $0(w<0.4)$ & $\begin{array}{c}\text { Class ? } \\
(0.4<w<0.6)\end{array}$ & Class $1(w>0.6)$ & \\
\hline 1 & 0 & 6 & 0 & 5 & 54,5 \\
\hline 2 & 0 & 11 & 0 & 0 & 100 \\
\hline 3 & 0 & 11 & 0 & 0 & 100 \\
\hline 4 & 0 & 11 & 0 & 0 & 100 \\
\hline 5 & 0 & 11 & 0 & 0 & 100 \\
\hline 6 & 1 & 5 & 0 & 6 & 54,5 \\
\hline 7 & 1 & 0 & 0 & 11 & 100 \\
\hline 8 & 1 & 0 & 0 & 11 & 100 \\
\hline 9 & 1 & 1 & 0 & 10 & 90,9 \\
\hline 10 & 0 & 4 & 0 & 7 & 36,3 \\
\hline 11 & 1 & 0 & 0 & 11 & 100 \\
\hline & & & & Overall: & 85,1 \\
\hline
\end{tabular}

\section{Conclusions}

Thermal imaging proved to be a good source of input data for neural networks - in case of this research, authors used three parameters of the steelmaking slag streams calculated directly from thermograms. After a series of tests, the neural network managed to obtain high classification efficiency, enabling to distinguish between streams with low and high FeO content. Previously it was necessary to perform chemical analyses to get this information. What is more, the proposed method is contactless, and does not require steelmaking slag samples to be taken. It is possible to apply this method in parallel with steelmaking slag pouring process in steelworks, without introducing any delay required for chemical analysis.

To improve classification efficiency, the neural network may be subjected to longer learning process, and more input parameters may be specified. Thermal camera may provide image with higher resolution, thanks to tele-conversion lens, which may grant more data to be sampled.

Preprocessing of input data to generate new parameters after linear or nonlinear transformation can be the next step in the overall procedure. It may enable getting less correlated data and data of the lower order. Two approaches are used, namely PCA (Principal Component Analysis) and LDA (Linear Discriminant Analysis) $[7,8,9]$.

\section{REFERENCES}

[1] Wiecek B., Strzelecki M., Jakubowska T., Wysocki M., Drews-Peszynski C., "Advanced Thermal Image Processing", Medical Devices and Systems, The Biomedical Engineering 1225 Handbook, Third edition; CRC Press 2006; str. 28-1 28-13.

[2] Wiecek M., Strakowski R., Jakubowska T., Wiecek B., Software for classification of thermal imaging for medical applications", 9th International Conference on Quantitative InfraRed Thermography, QIRT2008, Inzynieria Biomedyczna, vol. 14, $\mathrm{nr} 2 / 2008$.

[3] Ghosh A, Secondary Steelmaking, CRC Press, Boca Raton, London, New York, Washington, 2001.

[4] Strand J., Nakajima K., Eriksson R., Jonsson P., A Mathematical Model to Study Liquid Inclusion Behavior at the SteelSlag Interface, ISIJ International, vol. 45 (2005) No 12 s. 1838-1847.

[5] Bulkowski L., Wittchen W., Stecko J., Borecki M.: Wykorzystanie metody termowizyjnej do detekcji i odcinania żużla podczas spustu stali w procesie hutniczym Materiały V Krajowej Konferencji Termografia i Termometria w Podczerwieni, Ustroń, 14-16 listopada 2002 (in Polish).

[6] Stecko J., Borecki M., Bulkowski L., Wykrywanie żużla w konwertorach tlenowych za pomocą termowizji, HutnikWiadomości Hutnicze, nr 8, 2007, s. 402 - 406 (in Polish).

[7] A. Materka, M. Strzelecki, R. Lerski, L. Schad, Evaluation of Texture Features of Test Objects for Magnetic Resonance Imaging", Infotech Oulu Workshop on Texture Analysis in Machine Vision, June 1999, Oulu, Finland.

[8] B. F. J Manly, "Multivariate Statistical Method: A Primer". London, Chapman \& Hall, 1994.

[9] D. R. Causton, "A Biologist's Advanced Mathematics", London, Allen and Unwin, 1987. 